Research Article

\title{
Effect of Chip Segmentation on Cutting Forces at High Speed Milling of Al Alloys
}

\author{
S.Madhava Reddy ${ }^{\dot{A}}$, A.Chennakesava Reddy ${ }^{\dot{B}}$ and K.Sudhakar Reddy ${ }^{\dot{A}}$ \\ ${ }^{a}$ Associate Professor, Dept. of Mechanical Engg., Mahatma Gandhi Institute of Technology, Gandipet, Hyderabad-500 075. INDIA \\ ${ }^{\mathrm{B}}$ Professor of Mechanical Engineering, JNTUH, Hyderabad - 500 038.INDIA
}

Accepted 10 January 2014, Available online 01 February 2014, Special Issue-2, (February 2014)

\begin{abstract}
In this paper, an experimental study was performed to investigate the chip formation on cutting forces on aluminum alloy at different heat treatment states. Heat treatment (precipitation hardening) of Al-Si-Mg-Fe alloy is the essential parameter for continuous or segmented chip formation. Cutting speed and feed per tooth are the only cutting parameters with influence on the degree of segmentation in microstructures, leading to chip segmentation. Increasing cutting speed or feed per tooth leads to a more severe segmentation of the chips obtained from underaged material. While the chips obtained from overaged material remain continuous up to the highest cutting speed investigated. This investigation confirms that precipitation hardening is the key in changing from continuous to segmented chip formation and not only the cutting parameters. When machining the underaged microstructure, the degree of segmentation increases with a constant slope upto $7000 \mathrm{~m} / \mathrm{min}$ cutting speed. This study concludes that the relationship between chip formation and cutting forces using HSM.
\end{abstract}

Keywords: High speed end milling, cutting forces, Aluminum, Chip morphology

\section{Introduction}

Milling is a very commonly used manufacturing process in industry due to its versatility to generate complex shapes in variety of materials at high quality. Due to advances in machine tool, $\mathrm{CNC}, \mathrm{CAD} / \mathrm{CAM}$, cutting tool and high speed machining technologies in last couple of decades, the volume and importance of milling have increased in key industries such as aerospace, die and mold, automotive and component manufacturing (E.Budak, 2006). The need to reduce the manufacturing cost has led to higher demand for increased manufacturing productivity. High-speed machining (HSM) is now recognized as one of the most important manufacturing technologies for higher productivity, especially when the machining time is a significant fraction of the total cycle time. Moreover, due to reduction of the cutting force and the temperature of machined surfaces, HSM has the potential to produce certain part configurations, such as thin webs, that are not easily obtainable by conventional machining. One obvious benefit of HSM in general is that at high spindle speeds the feed can be increased proportionally for the same chip-load as in conventional machining. However, many issues related to tooling and machine tool design must still be addressed especially in speed ranges above $2000 \mathrm{~m} / \mathrm{min}$.

High-speed is a relative term varying from one work material to another making the definition of such a concept

*Corresponding author: S.Madhava Reddy

DOI: http://dx.doi.org/10.14741/ijcet/spl.2.2014.50 rather difficult. High -speed machining for a given material can be defined as that speed above which shearlocalization develops completely in the primary shear zone (C.Muller,R. Blumke, 2001). Advanced manufacturing technology of high silicon aluminum alloys has been identified as one of the manufacturing processes most in need of new developments to obtain the required improvements for a new generation of vehicles. The advantage of using high speeds in machining aluminum alloys stems from the fact that their melting points fall well below the temperature at which modern tool materials experience thermal softening. The potential for increasing high speeds in machining aluminum alloys at speeds up to $5000 \mathrm{~m} / \mathrm{min}$ is real and represents one order of magnitude increase over the current common practice in the automotive industry (M.Schultz,2000). Clearly, such a drastic increase in cutting speeds would result in significant productivity gains. Nevertheless, several key research issues must be addressed before the widespread industrial application of this new technology can be fully implemented.

The ability to accurately model the tool-chip interface during intermittent machining (milling) is necessary for the formulation of analytical and/or numerical process simulations that do not rely heavily on empirical information. Current, many models require an experimental determination of the cutting force coefficients that provide a fairly crude representation of the chip formation process and are specific to the workpiece material, tool geometry, and cutting conditions 
(La Baule, France S.Smith,J.Tlusty 1991). Komanduri et al. and Hou and Komanduri, 1982) reported a discontinuous transition from a continuous to a segmented chip formation. This transition is the result of a thermoplastic instability in the shear zone. Due to the transformation of high amounts of energy from deformation, in combination with short term processes, adiabatic conditions occur in the shear plane. The plastic deformation leads to a strength increase. At the same time the deformation work causes increased temperatures and leads to a thermal softening of the workpiece material in the shear plane. Due to the large amount of heat generated in the small shear plane the thermal properties can be assumed to be adiabatic and lead to high temperatures. If there is a balance between the thermal softening and the strength increase, due to plastic deformation, a sudden shearing of a chip segment will be caused (P. Li, Ma, C., Lai, Z., 1996). A group of authors see the reduction of shear strength caused by other effects. They assume that chip segmentation is caused by microcracks, due to the brittle behaviour of many materials when loaded with high deformation rates. Based on this theory, chip formation at high cutting speed is distinct by brittle fracture sensitivity in the workpiece material. By increasing cutting speed, the shear rate is higher and the contact area of two chip segments is decreasing. A further increase of the cutting speed leads to total separation of the two segments. A sudden decrease of cutting forces in the moment of segment formation and justified this with reduced shear band volume. In comparison to a cutting process with continuous chip formation, less deformation work is required (A Vyas,, Shaw, M.C., 1999). The transition from continuous to a segmented chip formation responsible for reduced cutting forces (H.Schulz, E.Abele, and A.Sahm, 2001). The influence of chip segmentation on cutting forces at high cutting speeds is not investigated until now. For this reason experimental investigations with different precipitation states of the workpiece material were conducted by end milling.

\subsection{Material}

The aluminium alloy Al-Si-Mg-Fe (composition in wt.\%: 9.0 Si, 3.5 Fe, $0.05 \mathrm{Cu}, 0.25 \mathrm{Mn}, 2.0 \mathrm{Mg}, 0.2 \mathrm{Cr}$, and $0.05 \mathrm{Ti}$ ) was received in the peak-aged T 6 condition. Underaged and overaged states were obtained by heat treatment. Annealing of the peak-aged material at $190^{\circ} \mathrm{C}$ for 18 hours produced an overaged microstructure.

Table 1 Mechnical properties of Al-Si-Mg-Fe at different precipitation states

\begin{tabular}{|l|l|l|l|}
\hline Microstructure & Underaged & $\begin{array}{l}\text { Peak } \\
\text { aged }\end{array}$ & Over aged \\
\hline $\begin{array}{l}\text { Hardness (Vickers } \\
\text { test) }\end{array}$ & 175 & 180 & 95 \\
\hline $\begin{array}{l}\text { Yield } \\
\text { strength(GPa) }\end{array}$ & 0.4 & 0.45 & 0.21 \\
\hline $\begin{array}{l}\text { Tensile Strength } \\
(\mathrm{GPa})\end{array}$ & 0.51 & 0.53 & 0.32 \\
\hline $\begin{array}{l}\text { Percentage } \\
\text { elongation (\%) }\end{array}$ & 8 & 6 & 10 \\
\hline
\end{tabular}

Solution heat treatment at $490^{\circ} \mathrm{C}$ for 60 minutes and subsequent quenching in ice water, followed by a 8 hour ageing treatment at $100^{\circ} \mathrm{C}$ produced an underaged state.

The peak aged state has the highest yield strength and tensile strength of the three microstructures, while it shows the smallest elongation at rupture. The overaged state shows half of the yield strength and twice the elongation of the peak aged state. The yield and tensile strength of the underaged alloy are in the same range as the corresponding values of the peak aged state, while the elongation increases.

\subsection{Machining parameters}

The machining investigations were conducted by vertical type machining center (figure 1). Straignt flute end milling cutters are used for milling. In order to develop monitoring functions, displacement sensors are installed on the spindle unit of high precision machining center. The PCD end milling cutter having four straight flutes was used in this investigation. The spindle has constant position preloaded bearings with oil-air lubrication and the maximum rotatational speed is $16000 \mathrm{rpm}$. The milling parameters were as follows: cutting speed $\mathrm{v}_{\mathrm{c}}=800$ to 8000 $\mathrm{m} / \mathrm{min}$, feed per tooth $\mathrm{f}_{\mathrm{z}}=0.1-0.3 \mathrm{~mm}$, depth of cut $=1$ $3 \mathrm{~mm}$.

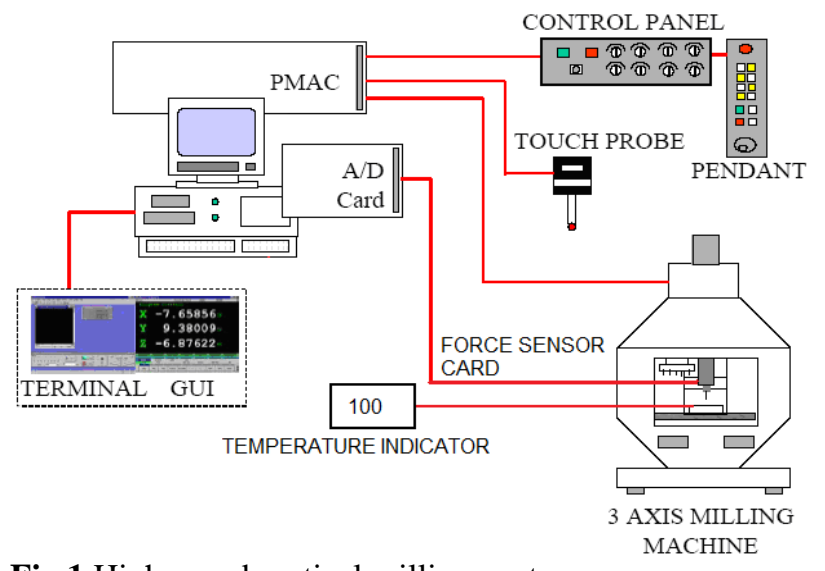

Fig.1 High speed vertical milling center

\subsection{Force Measurement}

For force measurement a 3-component dynamometer was used. The output signals were transformed into analogue voltage signals linear to force and sampled by a transient recorder. A sampling rate of $5 \mathrm{MHz}$ was chosen. Machining at constant contact frequency leads to a constant harmonic excitation at varying cutting speeds. Due to this, tamper concerning the dynamic response is constant at varying cutting speeds. During the tests, inserts were regularly distributed on the tool and the contact frequency was $256 \mathrm{~Hz}$. In the empty pockets inserts without a cutting edge were fixed. By applying inverse filtering, the signals of the cutting force will be corrected from distortions generated by dynamic response. To apply this strategy the dynamic response of the whole measuring chain was determined by exciting the $\mathrm{x}-$ and $\mathrm{y}-$ components. 


\section{Results and Discussion}

\subsection{Chip formation}

Chips obtained by milling, six chips were taken at random for microscopic examination. For further observations the chips were mounted longitudinally and metallographic sections were prepared at the Indian Institute of chemical Technology, Hyderabad. The occurring chip segmentation was characterized by the degree of segmentation defined as Gs $=(\mathrm{h} 1-\mathrm{h} 2) / \mathrm{h} 1$ (Figure 2). All measurements of the chip segmentation were carried out starting at the thicker end of the chip for 10 neighboring segments. Continuous or segmented chip formation is determined by the microstructure properties of the workpiece material, whereas machining parameters such as cutting speed and feed per tooth only determine the degree of segmentation.

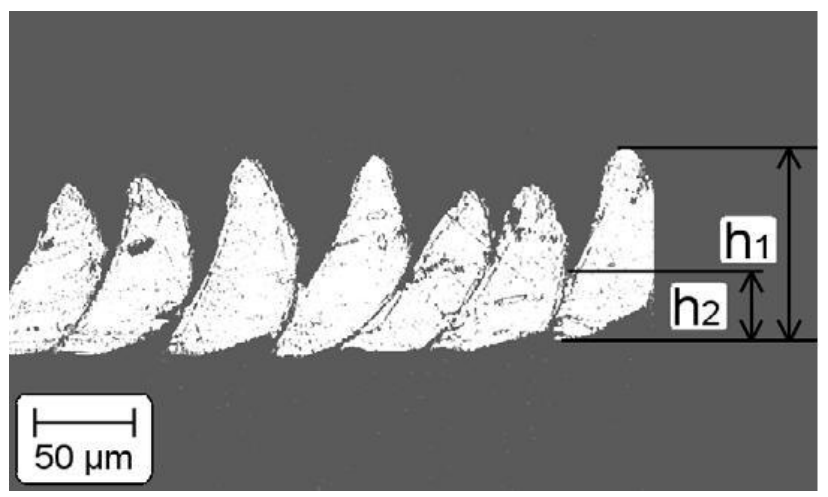

Fig. 2 Micrographic analyses to calculate degree of segmentation (milling, underaged state, $\mathrm{v}_{\mathrm{c}}=7000 \mathrm{~m} / \mathrm{min}$, $\left.\mathrm{f}_{\mathrm{z}}=0.2 \mathrm{~mm}\right)$.

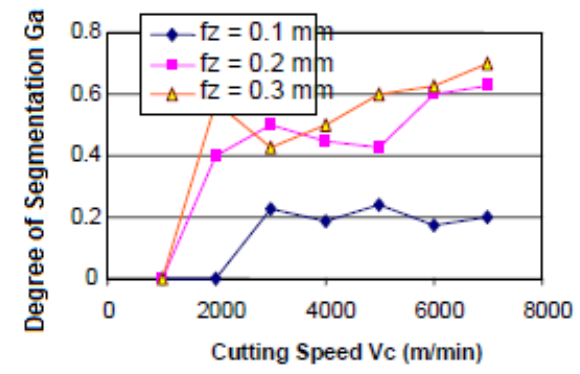

Fig.3 Influence of cutting speed and feed per tooth versus the degree of segmentation

The degree of segmentation (Figure 3) shows a dependency on cutting speed and depth of cut, formulated by the feed per tooth. At a feed per tooth of $0.1 \mathrm{~mm}$ segmentation starts at a cutting speed of $2000 \mathrm{~m} / \mathrm{min}$. A further increase in cutting speed up to $7000 \mathrm{~m} / \mathrm{min}$ cutting speed leads to 0.2 degree of segmentation. Investigations at a feed per tooth of 0.2 and $0.3 \mathrm{~mm}$ already show a degree of segmentation of approximately 0.4 at cutting speed of $2000 \mathrm{~m} / \mathrm{min}$. By increasing cutting speed, degree of segmentation rises with a small slope up to 0.7 . When machining the peak-aged material, the chips show no uniform chip formation. At high cutting speeds, parts of the chips are found to be mostly segmented with some continuous regions blended in Figure 4a. Systematic variation of the microstructure on the workpiece material reveal, that the microstructure has a dominating influence on chip formation in high speed machining for continuous and interrupted cutting.
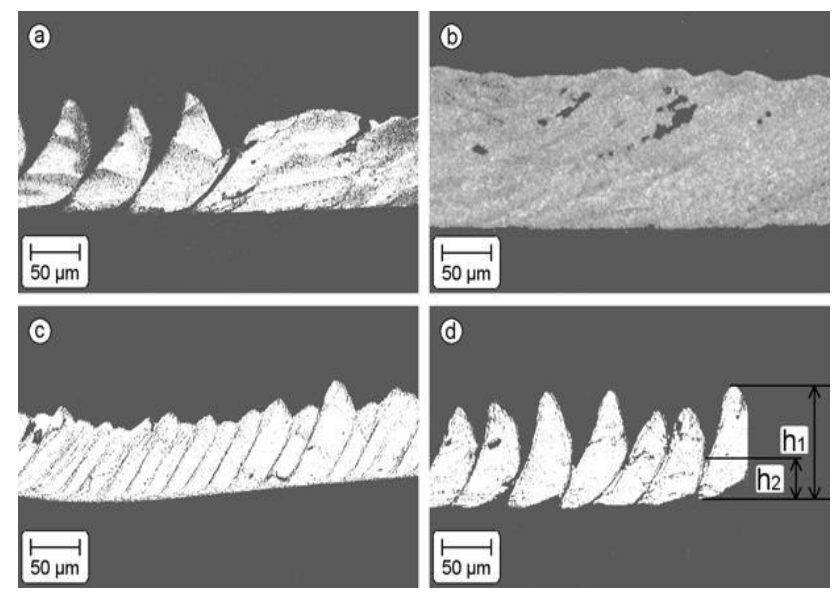

Fig.4 Micrographs of chips obtained by machining of different ageing states of Al-Si-Mg-Fe (a) peak aged, $\mathrm{v}_{\mathrm{c}}=$ $7000 \mathrm{~m} / \mathrm{min}$, (b) overaged, $\mathrm{v}_{\mathrm{c}}=7000 \mathrm{~m} / \mathrm{min}$; ; underaged, $\mathrm{v}_{\mathrm{c}}=1000 \mathrm{~m} / \mathrm{min},(\mathrm{c})(\mathrm{d})$ underaged, $\mathrm{v}_{\mathrm{c}}=7000 \mathrm{~m} / \mathrm{min}$,

Chips obtained from overaged microstructure show a continuous chip formation over the whole length of the chip, independent of the cutting speed. Even in combination of highest cutting speed $(7000 \mathrm{~m} / \mathrm{min})$ and highest feed per tooth $(0.4 \mathrm{~mm})$, the primary shear deformation is homogeneous and no tendency of segmentation can be observed (Figure 4b).

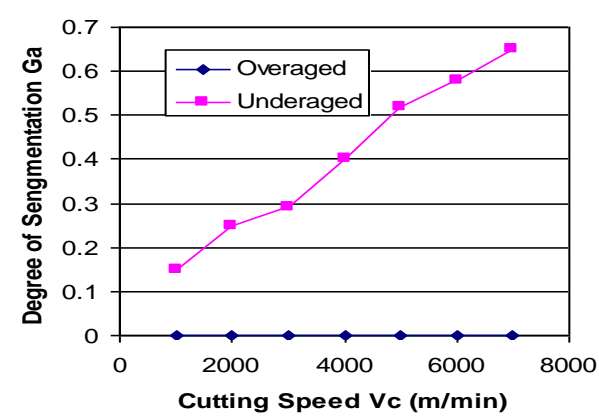

Fig.5 Degree of segmentation at different precipitation stages and cutting speeds

In case of underaged material, segmentation occurs at all cutting speeds. At $\mathrm{v}_{\mathrm{c}}=1000 \mathrm{~m} / \mathrm{min}$ and $\mathrm{f}_{\mathrm{z}}=0.2 \mathrm{~mm}$, darketching shear bands are visible at an angle of approximately $60^{\circ}$ to the underside of the chip, representing sites of localised primary shear deformation within the chip (Figure 4c). At the highest cutting speed investigated $(7000 \mathrm{~m} / \mathrm{min})$, the separation of the segments is almost complete at $\mathrm{f}_{\mathrm{z}}=0.2 \mathrm{~mm}$ (Figure $3 \mathrm{~d}$ ). Figure 5 shows the degree of segmentation at different cutting speeds for under and overaged precipitation states. When machining the underaged microstructure, the degree of segmentation increases with a constant slope up to 7000 $\mathrm{m} / \mathrm{min}$ cutting speed. In contrast, overaged microstructure shows an almost constant degree of segmentation of 0 for 
cutting speeds up to $7000 \mathrm{~m} / \mathrm{min}$. A transition from continuous to segmented chip formation was not found for any precipitation state up to cutting speeds of 8000 $\mathrm{m} / \mathrm{min}$. The initiation of localised shear bands during chip formation of the underaged microstructure is thought to be a consequence of local work softening caused by shearing of coherent precipitates by dislocations.

\subsection{Effect of Cutting speed on Cutting forces}

The effect of cutting speed on the resultant cutting force is shown in figure 6 . It is observed that the decreasing cutting forces by increasing cutting speeds, in segmented and continuous chips.

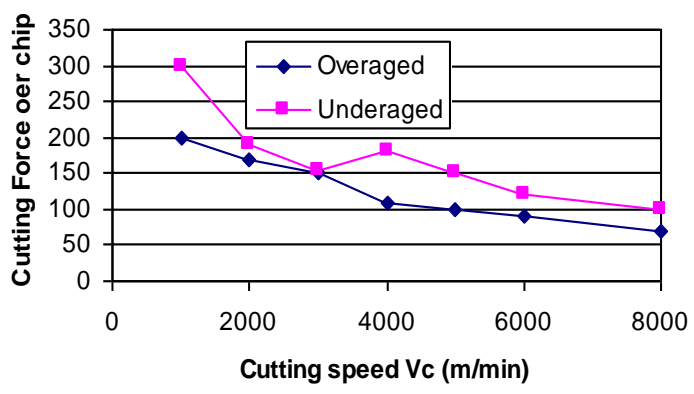

Fig.6 Influence of different precipitation stages and cutting speeds on the average cutting force per chip.

In order to eliminate any influence of the measuring system, turning investigation on both precipitation were conducted. The results confirm that for both, continuous and segmented chips, cutting forces decrease at high cutting speeds. As in milling, continuous chips were obtained when machining overaged, and segmented chips for underaged chips for the precipitation state.

At low and high cutting speed the difference in cutting forces is decreasing (figure 7). In the midrange the difference is getting much higher. This difference could be justified by effects in the secondary shear zone. The incoherent precipitates of the overaged state allow a redistribution of slip, leading to a homogeneous plastic deformation and therefore to the development of continuous chips.

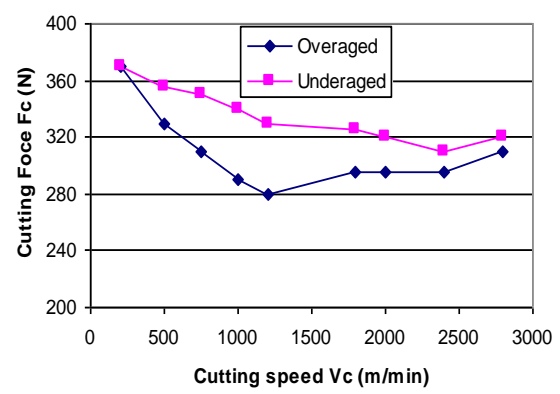

Fig.7 Influence of different precipitation stages and cutting speeds on the cutting force

By using workpiece material with defined properties of microstructure and chip formation, the influence of chip segmentation on cutting forces has been investigated. The results for both, milling and turning show, that cutting forces are decreasing with higher cutting speeds for continuous and segmented chip formation. Due to this, other effects during chip formation are dominating the cutting forces. It is assumed that these effects occur in the secondary shear zone, because systematic variation of microstructural properties mostly effects the primary shear zone.

\section{Conclusions}

High speed milling experiments have been performed with various microstructures of $\mathrm{Al}-\mathrm{Si}-\mathrm{Mg}-\mathrm{Fe}$ for different machining technologies and parameters such as cutting speed and feed rate. The influence of heat treatment, machining and cutting parameters can be summarised as follows:

1) Cutting speed and feed per tooth are the only cutting parameters with influence on the degree of segmentation in microstructures, leading to chip segmentation.

2) Heat treatment (precipitation hardening) of $\mathrm{Al}-\mathrm{Si}-\mathrm{Mg}-\mathrm{Fe}$ is the essential parameter for continuous or segmented chip formation.

3) The precipitation state determines the chip formation. A underaged precipitation state leads to segmented chips, continuous chips are obtained for the overaged state.

4) Chip segmentation had no dominating influence on cutting forces, when machining $\mathrm{Al}-\mathrm{Si}-\mathrm{Mg}-\mathrm{Fe}$ in under- and overaged precipitation state in milling and turning.

5) Increasing cutting speed or feed per tooth leads to a more severe segmentation of the chips obtained from underaged material, while the chips obtained from overaged material remain continuous up to the highest cutting speed investigated.

\section{References}

E.Budak, (2006), Analytical models for high performance milling. PartI: cutting forces, structural deformations and tolerance integrity, Int.Journal of Machine tools \&Manufacturing, Vol.46, pp.14781488 ,

C.Muller,R. Blumke, (2001), Influence of heat treatment and cutting speed on chip segmentation of age hardenable aluminum alloy, Material Science and Technology, vol.17,

M.Schultz, (2000), Limits for the application of long protruding tools regarding the process stability and safety, Procedings of the second International seminar on improving machine tool performance

La Baule, France S.Smith,J.Tlusty,( 1991), An overview of modeling and simulation of the milling process, Transaction of the ASME Journal of Engineering for Industry, vol.113, pp.169-175

R. Komanduri, Schroeder, T., Hazra, J., von Turkovich, B. F., Flom, D. G., (1982), On the Catastrophic Shear Insability in High-Speed Machining of an AISI 4340 Steel, Journal of Engineering for Industry, Vol.104: pp. 121-131.

Z Bing Hou, Komanduri, R., (1997), Modelling of thermomechanical shear instability in machining, Int. J. Mech. Sci., Vol. 39/11: pp.1273-1314

P. Li, Ma, C., Lai, Z., (1996), Strain evaluation model of adiabatic shear band produced by orthogonal cutting in high strength low alloy steel, Materials Science and Technology, Vol.12: pp.351-354.

A Vyas,, Shaw, M.C., (1999), Mechanics of Saw-Tooth chip Formation in Metal Cutting, J. Manufact. Sci. Eng., Vol.121, pp. 163-172.

F. Klocke, ZinkannV, (1999), Hoch- Geschwin digkeitsbearbeitung ändert die Span-bildung, VDI-Z, 141:30-34

H.Schulz, E.Abele, and A.Sahm, (2001), Material aspects of chip formation in HSC machining, Annals of the CIRP, Vol.50(1), pp.45-48

Yuan Ning, M.Rahman and Y.S wong,(2001), Investigation of chip formation in High speed end milling, Journal of materials processing technology, Vol.113, 2001, pp.360-36

W.Konig, D.Erinski, and RWTH Aachen, Machining and machinability of Aluminium alloys, Annals of the CIRP, vol.32, issue 2, pp.535-5

Serope Kalpakjian and Steven R.Schmid, (2012), Manufacturing Engineering and Technology, Fourth Edition, Pearson Publishers. 